\title{
Усиление рамановских диссипативных солитонов в фосфоросиликатных оптических волокнах
}

\author{
Д.С. Харенко $^{1, *}$, И.С. Жданов ${ }^{1,2}$, М.С. Мишевский ${ }^{2}$, А.Е. Беднякова ${ }^{2,3}$ \\ ${ }^{1}$ Институт Автоматики и Электрометрии СО РАН \\ ${ }^{2}$ Новосибирский Государственный Университет \\ ${ }^{3}$ Институт Вычислительных Технологий СО РАН \\ *E-mail: kharenko@iae.nsk.su
}

DOI: 10.31868/RFL2020.99-100

На сегодняшний день наблюдается повышенный интерес к ультракоротким импульсам на длинах волн в области 1.3 мкм, что связано с перспективами их применения для многофотонной микроскопии биологических объектов [1]. Существует несколько методов получения такого излучения: с помощью новых активных сред (висмут, празеодим) [2,3], с использованием параметрических усилителей [4], а также посредством генерации рамановских диссипативных солитонов (РДС) в фосфоросиликатных оптических волокнах [5]. Ранее нами была показана возможность генерации импульсов с несущей длиной волны вблизи 1.3 мкм и энергией до 2.5 нДж во внешнем резонаторе. Последующий численный счёт, в котором импульс накачки мог иметь произвольные ширину спектра и энергию, не показал существенного увеличения энергии генерируемых РДС [6]. Таким образом, актуальной задачей является исследование возможности последующего усиления РДС, и наиболее простым способом её решения в нашем случае является усиление с использованием эффекта ВКР в том же самом фосфоросиликатном волокне (синхронное усиление).
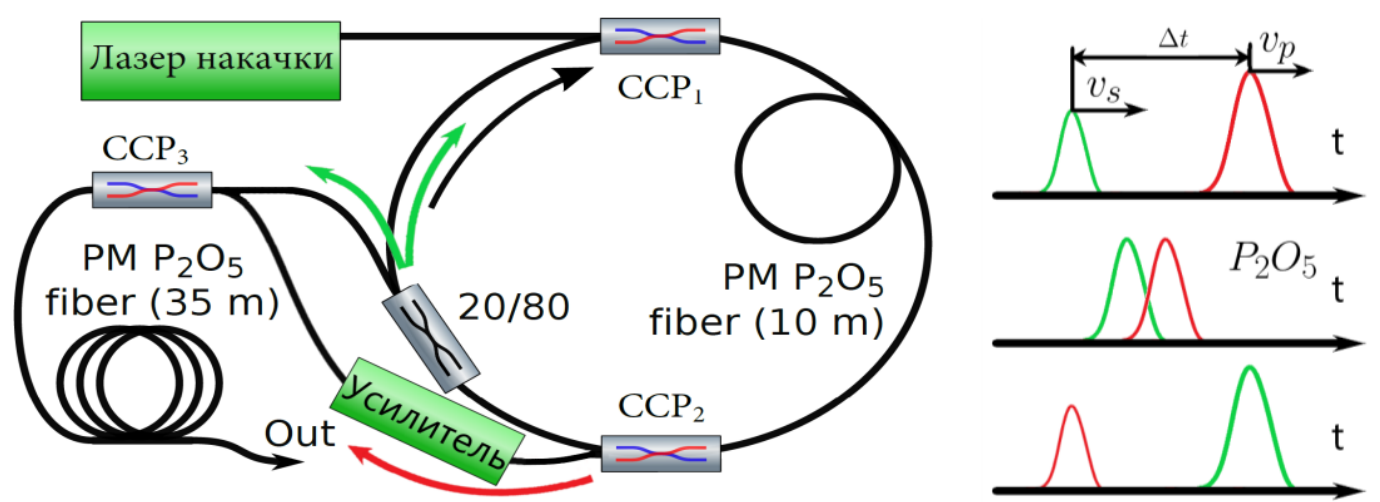

Рис. 1. Схема генерации и усиления РДС (слева), схематичное изображение взаимодействия импульса сигнала $(s)$ и накачки $(p)$ в фосфоросиликатном волокне (справа)

Схема генерации и усиления РДС приведена на Рис. 1. Для усиления РДС использовался непоглощённый импульс накачки, выведенный из резонатора дополнительным спектрально-селективным ответвителем и усиленный в иттербиевом волокне. Эффективное усиление посредством ВКР возможно только при условии полного прохождения импульсов друг через друга (из-за разности групповых скоростей) в отрезке фосфоросиликатного волокна на выходе. Процесс усиления схематично представлен на Рис. 1 справа, где $\Delta t-$ это задержка между импульсами, а $v_{s}$ и $v_{p}$ обозначают групповые скорости сигнала и накачки соответственно.

Предварительные результаты представлены на Рис. 2. Слева приведены оптические спектры РДС для различных задержек между импульсами сигнала и накачки на выходе в случае отсутствия дополнительного усилителя. Здесь явно 
виден эффект усиления посредством ВКР, когда перекрытие импульсов максимально (линия для 50 пс). Интегрально энергия возросла в полтора раза, чего не достаточно для реальных применений. К тому же значительно увеличился разброс между различными спектральными компонентами, что можно объяснить влиянием импульса накачки, который оказывается довольно изрезанным, и узостью самого пика рамановского усиления. Большее усиление РДС можно достигнуть с более мощным импульсом накачки, для чего в схему был установлен дополнительный усилитель (см. нижнее плечо на Рис.1). Оптические спектры для этого случая представлены на Рис.2 справа. Видно, что мощность импульса выросла на величину порядка 3 дБ, но из-за дополнительных потерь на оптических элементах выигрыш в абсолютных величинах оказался незначительным. Кроме того, доля прошедшей накачки составила почти $80 \%$.
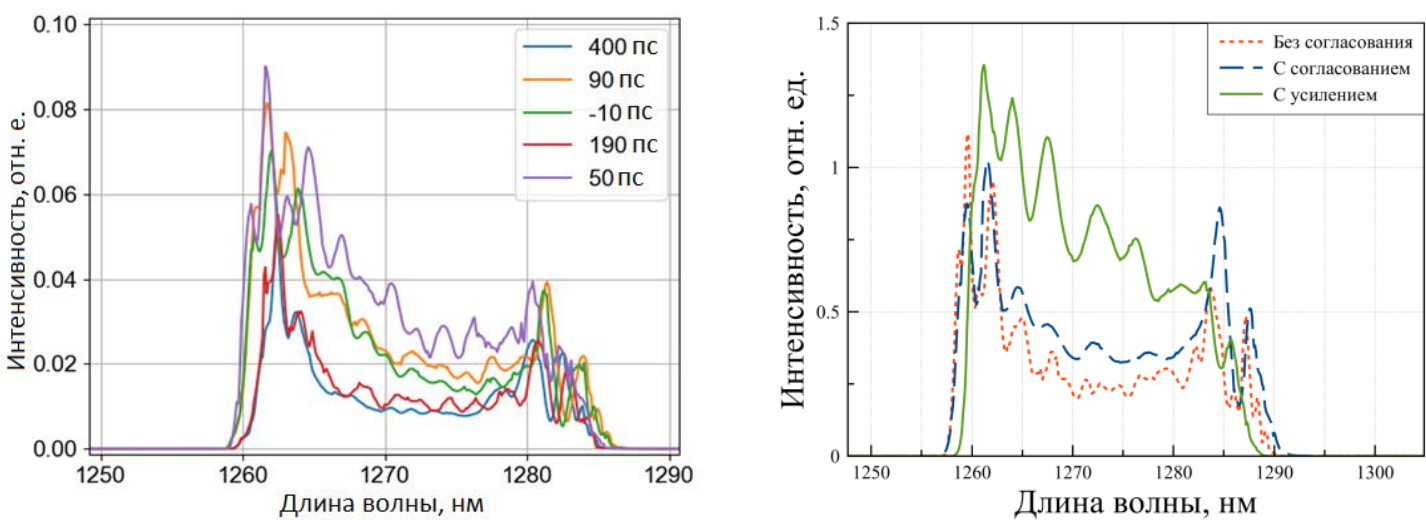

Рис. 2. Спектры на выходе в зависимости от оценочной задержки между импульсами накачки и сигнала (слева), спектры сигнала после усиления с дополнительным усилением накачки (справа)

Несмотря на то, что на текущем этапе добиться высокого коэффициента усиления не удалось, у реализованной схемы есть потенциал для дальнейших исследований. Например, можно получить большее усиление импульса накачки путём подавления генерации спонтанного сигнала, или оптимизировать величину линейной частотной модуляции (чирпа) импульсов. Возможно также и использование непрерывной накачки и большего отрезка фосфоросиликатного волокна.

Исследование выполнено при финансовой поддержке РФФИ в рамках научного проекта № 20-32-70093.

\section{Литература}

[1] C. Xu, F. W. Wise, Nature Phot. 7, 875 (2013)

[2] А. М. Хегай, Ф. В. Афанасьев и др., Квантовая электроника 46, 1077 (2016).

[3] H. Ahmad, S. N. Aidit and Z. C. Tiu, Opt. Laser Technol. 112, 20 (2019).

[4] Y. Qin, Y-H Ou, et al, Optics letters 44, 3422 (2019)

[5] Д. С. Харенко, В. Д. Ефремов и С. А. Бабин, Квантовая электроника 49, 657 (2019)

[6] A. E. Bednyakova, D. S. Kharenko et al, Opt. Express 28, 22179 (2020) 